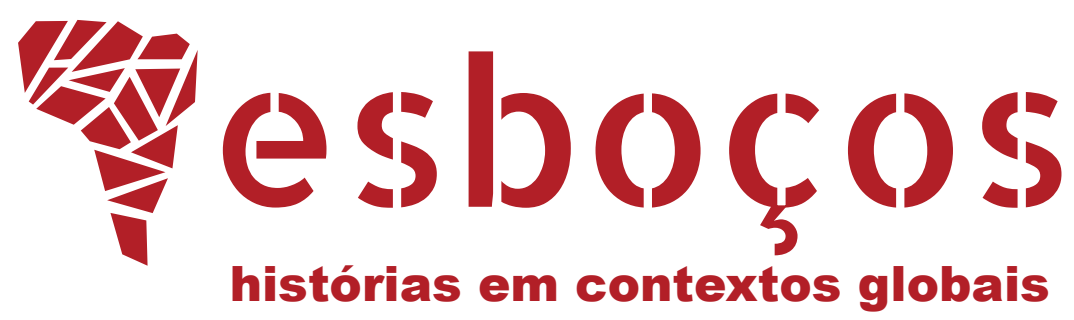

\title{
HISTÓRIA DA HISTORIOGRAFIA \\ E PERSPECTIVA GLOBAL: UM \\ DIÁlOGO POSSÍVEL?
}

History of Historiography and Global Perspective: a Possible Dialogue?

Jurandir Malerba ${ }^{\mathrm{a}}$

(1) https://orcid.org/0000-0001-7118-0182

E-mail: jurandirmalerba1@gmail.com

a Universidade Federal do Rio Grande do Sul, Instituto de Filosofia e Ciências Humanas, Departamento de História, Porto Alegre, RS, Brasil

\section{DEBATE}

História da historiografia em perspectiva global 


\section{RESUMO}

Partindo da análise de dois empreendimentos realizados no campo da história da historiografia e das histórias globais da historiografia de Georg lggers, Q. Edward Wang e Daniel Woolf, neste artigo se propõe pensar o escopo e os fundamentos da história global, evidenciando possíveis contradições e obstáculos conceituais dessa perspectiva de investigação histórica, como a resiliência do eurocentrismo, o determinismo dos vieses nacionais e os limites culturais impostos pelo domínio de idiomas.

\section{PALAVRAS-CHAVE}

História global. História da historiografia. Teoria da história.

\section{ABSTRACT}

Based on the analysis of two studies carried out in the field of history of historiography and global histories of historiography by Georg Iggers, Q. Edward Wang and Daniel Woolf', this article aims to reflect on the scope and rationale of global history, shedding light on possible conceptual obstacles and contradictions of such perspective of investigation, such as the resilience of Eurocentrism, the determinism of national perspectives and the cultural limits imposed by language mastery.

\section{KEYWORDS}

Global history. History of historiography. Theory of history. 
ste texto exige ser aberto com duas ou três ressalvas. Primeiro, foi originalmente pensado para ser falado e ouvido, não lido. Essa informação diz muito de sua forma e de seus limites. Mais do que pelo fato de ser narrado em primeira pessoa, seu teor é propositalmente provocativo, irônico às vezes, demasiado hiperbólico e generalista, intuitivo. Mais próximo da forma ensaio do que do protocolar artigo científico. Assim, trata-se de um pensar em voz alta, que pela provocação convida a audiência a pensar questões de fundo sobre a história global como campo historiográfico. Por outro lado, importa salientar que eu mesmo não sou um "autor global", ou um historiador que pesquise nesse campo ou com base nessa perspectiva. As ponderações a seguir apresentadas são as de um outsider, munido apenas de algumas ferramentas da caixa da teoria da história. Feitas essas ressalvas, quase captatio benevolentiae, o texto que segue espera um leitor indulgente. Busco falar de história da historiografia sob um viés global com uma postura assumidamente provocativa aos historiadores da área.

No campo historiográfico, é comum a dialética de negações e afirmações de projetos intelectuais, de modo que, de tempos em tempos, alguém descobre a pólvora, nega tudo o que se fazia antes por obsoleto e passa a predicar o que a história deverá ser doravante. Desde a primeira metade do século XIX, Ranke, Droysen e depois toda a tradição do Historik levantaram a bandeira de que a história tinha de ser uma ciência ou não seria nada. Nas primeiras décadas do século XX, os fundadores dos Annales sinalizaram que a história deveria ser uma ciência social, uma história-problema, das estruturas, ou não seria nada. Duas gerações depois, fascinado com a capacidade de gerenciamento de dados dos computadores, em sua aula inaugural no College de France ("A história imóvel"), o historiador Emmanuel Leroy Ladurie profetizou: "O historiador de amanhã será um programador ou nada será” (LADURIE, 1974, p. 673-692).

Uma das poucas vantagens de envelhecer - se é que isso é lá alguma vantagem - é que, depois de anos e décadas, muita coisa já se viu passar. Iniciei minha vida como historiador quando se era marxista ou não se era nada. Com a abertura democrática nos anos 1980, o sujeito era um historiador cultural (das "mentalidades") ou não era nada (era um dinossauro que trabalhava com fósseis como estruturas econômicas e sociais ou luta de classes).

Vi bandos de historiadores que deixaram de ser "locais" ou "regionais" para virar "micro-historiadores". Descobrimos que história do Estado e da esfera pública era normativa e coercitiva e nos voltamos para a vida privada, a intimidade e as subjetividades. A velha história das ideias ficou obsoleta, e viramos todos historiadores conceituais. A história ciência se esgotou, e voltamos a ser historiadores narrativos.

As modas vão surgindo e se sucedendo. Eu mesmo estive num evento na Universidade Federal Fluminense (UFF) em 2014 sobre "história pública" em que ouvi, em várias exposições de alto nível, o mesmo vaticínio: dada a reconfiguração do espaço público subvertido pelas plataformas digitais, no futuro todo historiador haverá de se tornar público. Não são poucos os colegas hoje que proclamam que a história disciplinar acabou e só restaram dela os usos políticos presentes do passado. Somos todos presentistas ou não somos nada.

No caso da história global, essa questão foi colocada a David Armitage, assim que ele assumiu cátedra em Harvard, numa longa entrevista concedida a Martine Van Ittersum e Jaap Jacobs, publicada na revista Itinerario, em 2012: "Somos todos 
historiadores globais agora?". A essa pergunta, ele respondeu com a agressividade de quem peleia numa guerra de conquista de território:

\begin{abstract}
A hegemonia da historiografia nacional terminou. [...] Agora, nós temos que perguntar aos historiadores nacionais: por que você está fazendo história americana independentemente da história do hemisfério, do império americano, das relações dos Estados Unidos com o resto do mundo, a história do Emigração americana, a circulação transnacional de ideias, seja ela qual for? Acho que é hora de colocarmos os historiadores nacionais na defensiva, para justificar sua escolha de marcos locais, regionais ou nacionais especificos (ARMITAGE, 2012, p. 16, grifo nosso).
\end{abstract}

Nessa argumentação de caráter teórico e historiográfico, propor qualquer balanço dessa vertente relativamente nova denominada "história global" seria falta de astúcia. Nos últimos quinze ou vinte anos, muitos autores vieram tentando "delimitar o campo": Michel Geyer e Charles Bright (1995), no texto pioneiro "World history in a global age"; Patrick O'Brien (2006), em seu apelo "Historical traditions and modern imperatives for the restoration of global history", feito no primeiro volume do Journal of Global History; e Maxine Berg (2013), que editou Writing the History of the Global: Challenges for the $21^{\text {st }}$ Century. ${ }^{1}$

Poderíamos incluir nesse levantamento sumário "História global: um empreendimento intelectual em curso" (2017), artigo de João Júlio Gomes dos Santos e Monique Sochaczewski, que é o melhor balanço do estado da arte entre nós e que, olhando para América Latina e o Brasil, leva aos historiadores globais a dúvida quanto a se somos parte do West ou do Rest; "Tradições de história global na América Latina e no Caribe" (2015), de Rafael Marquese e João Paulo Pimenta, ou "Brazilian History as Global History" (2018), de Frederick Shulze e Georg Fisher.

Propor isto - discutir a historiografia global -, mais do que uma tarefa ingrata, seria uma armadilha, pois exigiria um lastro que não tenho. Em vez disso, vou comentar algumas tentativas de aplicação do escopo e dos procedimentos da história global ao campo com o qual tenho um pouco mais de familiaridade: a história da historiografia. Desses casos, apenas rapidamente mencionados, vou me deter um pouco mais em dois. À análise, seguem-se as provocações finais.

\title{
ACEPÇÕES DE “GLOBAL” NA HISTÓRIA DA HISTORIOGRAFIA
}

Há uma longa tradição de histórias da historiografia, cujo início remonta pelo menos ao século XIX. Como acontece com qualquer outra especialidade do conhecimento histórico, cada época propõe problemas e abordagens, investiga e narra a história - da historiografia, nesse caso - à sua maneira. As primeiras histórias das historiografias

\footnotetext{
${ }^{1}$ Essa obra, em particular, pretende estabelecer as balizas de circunscrição de um campo, como convém a um programa. Tem uma primeira parte mais "conceitual", teórica, sobre o que está implicado no "fazer história global"; uma segunda, sobre metodologias da história global; mais outras, sobre a modulação do conceito (e questões de escala, objetivos e categorias), do objeto ("Global objects: contention and entanglement") e do método (comparativo); e uma última, sobre caminhos a percorrer e desafios a vencer (globo e império, globo e identidade, resiliência dos Estados nacionais). Enfim, um programa!
} 
apareceram praticamente junto com a consolidação da história como campo disciplinar, no fim do século XIX - e, portanto, estão conectadas com o processo histórico de construção dos Estados e formação das nações, a partir da Europa.

Desde os trabalhos de Robert Flint $(1893),{ }^{2}$ com variações de ênfases, as grandes histórias da historiografia, como G. P. Gooch (1913), Feuter (1915), ${ }^{3}$ Harry Elmer Barnes (1922), James Shotwell (1936), o consagrado Robin George Collingwood - The Idea of History (1946) $-{ }^{4}$ até um dos mais recentes empreendimentos nesse sentido, como a obra organizada por Aviezer Tucker e publicada pela Blackwell em $2009,{ }^{5}$ seguem a mesma lógica de composição. O que todas essas histórias da historiografia têm em comum? $\mathrm{O}$ fato de, mais do que serem escritas de pontos de vista nacionais, são de todo eurocêntricas.

Muito tardia e recentemente, porém, esse sestro vem sendo superado. Temos um Comitê Internacional de Ciências Históricas ( $\mathrm{CISH}$ ) que existe desde a década de 1920, quando a história global era um tema bastante marginal. Só na conferência de Amsterdã em 2010 é que o CISH aceitou um subcomitê para a história global e mundial entre suas subdivisões especializadas - refletindo, de algum modo, o boom que a história global experimentou desde o fim da década de 1990, primeiro no mundo anglo-saxão e depois em outras partes (HIRSCHI, 2012). Tal fenômeno indica, em alguma medida, o interesse crescente na história global por todo lado, nos dias de hoje, mas também - o que mais me interessa neste momento - a aplicação de perspectivas globais em todos os subcampos da historiografia, incluindo o estudo da própria escrita da história.

\footnotetext{
${ }^{2} \mathrm{Na}$ verdade, Flint faz propaganda enganosa. Apesar daquele primeiro título que vem na capa, History of the Philosophy of History, segue outro, que seria o mais apropriado: Historical Philosophy in France and French Belgium and Switzerland. São 706 páginas. Na introdução, há um subcapítulo intitulado "Political conditions in Egypt and Assyria unfavourable to the development of historiography". Entre as páginas 44 e 49, abordam-se historiografia e historiadores na China, no Japão e na Índia, bem como os "registros históricos judeus". Chega-se então à Grécia. Depois de passar pela Idade Média e incluir 14 páginas sobre Ibn Khaldun, o livro começa de fato à página 176: "The Philosophy of History in France", e segue com Bodin; Bossuet; uma síntese do século XV ao XVIII (Montesquieu, Turgot, Voltaire, Rousseau e Condorcet), para chegar ao século XIX e suas "escolas": Romantismo (Chateaubriand, Mignet, Thiers, Thierry), ultramontanismo católico, escola liberal e socialista, "escola democrática (Michelet, Quinet), naturalismo, positivismo (Comte e discípulos), escola crítica (Seignobos, Tarde, Coulanges) etc.

${ }^{3}$ Histoire de L'Historiographie Moderne é dividido, por sua vez, em seis "livros": $1^{\circ}$ a historiografia humanista na Itália (até a contrarreforma), $2^{\circ}$ a expansão da historiografia humanista através da Europa e a história política nacional (França, Inglaterra/Escócia, Alemanha, Suíça, Espanha), $3^{\circ}$ a historiografia independente do humanismo até o "século das luzes", $4^{\circ}$ a historiografia do racionalismo, $5^{\circ}$ a historiografia do romantismo e do liberalismo; $6^{\circ}$ a reação realista contra a historiografia romântica e a influência do movimento social.

${ }^{4}$ Aideia de história é dividida em cinco partes: "Historiografia greco-romana", "Ainfluência do cristianismo", "O limiar da história científica", "A história científica" e "Prolegômenos", esta a que sobreviveu e que permanece como contribuição decisiva incorporada ao patrimônio da teoria.

${ }^{5}$ Depois das partes conceituais iniciais, que definem grandes campos, problemas básicos e subcampos da filosofia da história e da historiografia, vem a parte 4, sobre escolas clássicas e filósofos da historiografia e da história (capítulos 34 a 50), de Darwin; empirismo lógico e positivismo lógico; filosofia da história judaico-cristã; Vico, Kant, Herder, Hegel, Marx, Croce; fenomenologia, hermenêutica e pós-modernismo. O único ponto fora da curva eurocêntrica é o capítulo 39, "Muslim Philosophy of History", de Zaid Ahmad.
} 
A história global, em suas formulações mais sofisticadas, não significa contar a história de tudo no mundo todo. Podemos partir do entendimento de que "global" não é o objeto de estudo, qualquer que seja, mas uma ênfase nas conexões, na escala e, acima de tudo, na integração. ${ }^{6}$ Não é difícil imaginar uma história de mercados mundiais ou bolsas de valores numa economia global; uma história de disseminação de tecnologias como o telégrafo, o cabo marítimo ou a internet, conectando diferentes regiões do mundo; uma história de migrações e diásporas de populações sobre o globo; uma história dos hábitos alimentares ou da propagação de doenças mundo afora; uma história da guerra, com batalhas sucedendo simultaneamente em diferentes continentes.

No caso de uma história global da historiografia, no entanto, o desafio particular reside no fato de que, até recentemente, se acreditava que a autoconsciência histórica das sociedades, assim como a história como atividade acadêmica, teria surgido no Ocidente, sendo depois incorporada e interpretada como elemento central de modernização mundo afora, seguindo padrões ocidentais. Esse "ocidentalismo", se quisermos, ou eurocentrismo, como vimos, está presente em todas as histórias da historiografia desde o século XIX e ao longo do XX. No fim dos anos 1980, alguns teóricos e historiadores da historiografia, como Jörn Rüsen e Georg lggers, começaram a manifestar a necessidade de superação dessa limitação, a fim de produzir uma história da historiografia transcultural. ${ }^{7}$

Só a partir da primeira década dos anos 2000 é que começam a surgir iniciativas de maior fôlego para uma escrita global da história da historiografia. Uma delas é a série em cinco volumes da Oxford History of Historical Writing (2011), editada por Daniel Woolf e Alex Schneider, que procura cobrir a história da escrita histórica em todas as épocas e continentes. Do trabalho de organização dessa obra certamente vieram os subsídios para que um de seus organizadores, Daniel Woolf, publicasse seu volume autoral Uma história global da história (2011, 2014). Aqui, uma pergunta que não quer calar: por que o mesmo Woolf, que encabeçou uma obra coletiva imensa, se sentiu obrigado a escrever a própria versão, autoral, do mesmo assunto? Essa questão fica em aberto.

Neste artigo, analiso essa obra autoral de Woolf. Mas, antes dela, examino A Global History of Modern Historiography (2008), livro escrito por Georg Iggers e Edward Wang. ${ }^{8}$

\footnotetext{
${ }^{6}$ Jeremy Adelman (2017) aponta justamente o começo do fim da história global nesse contexto de "desintegração" mundial e de retorno dos nacionalismos de direita (America first, China first, Brexit etc). ${ }^{7}$ Por todos, ver a coletânea organizada por Rüsen (2002), em que colaboram Tarif Khalidi, Klaus Müller, P. Burke, Aziz Al-Azmeh, Hartog, Ankersmit, Iggers, Masayuki Sato, Mamadou Diawara, Ying-shih Yü, Romila Thapar, entre outros. Ver também Rüsen (2006).

${ }^{8}$ Tenho notícia de que há pelo menos uma terceira obra autoral que pretende fazer uma história global da historiografia, de Markus Völkel (2006). Mas a ela não tive acesso.
} 


\section{HISTÓRIAS GLOBAIS DAHISTORIOGRAFIA: OS "CASOS” IGGERS/WANG E WOOLF}

O livro de Georg Iggers e Q. Edward Wang, com a participação de Supriya Mukherjee (IGGERS; WANG; MUKHERJEE, 2008), ${ }^{9}$ trouxe uma contribuição sem precedentes para os estudos históricos. Sua análise das linhas de força da historiografia contemporânea é francamente amparada numa abordagem de global history, ou seja, de que, desde o advento da modernidade, vivemos numa época de globalização e que os modos contemporâneos de escrever história trazem essa marca de nosso tempo. Mais do que isso, defende que esse processo de globalização se caracteriza pela ocidentalização dos modos de pensar e produzir história. Sua análise é comparativa, mais do que um mero recitativo ou uma catalogação de historiografias ou autores regionais ou nacionais.

Um acerto estratégico do livro está no método escolhido, que impõe aos autores tratarem a história da historiografia dentro de um período que permita a abordagem global e comparativa desejada; portanto, desde fins do século XVIII - quando as várias tradições historiográficas ocidentais e orientais começam a se conectar - até os dias de hoje. O foco da obra incide nas interações de diversas tradições historiográficas ocidentais e não ocidentais num contexto global. Se, no início do período estudado, as trocas transculturais são poucas, elas se intensificam vertiginosamente a partir do fim do século XIX, no sentido do que os autores entendem como processos (no plural) de ocidentalização das historiografias não ocidentais, uma vez que esses processos são múltiplos, diversos, compreendendo desde a difusão dos paradigmas racionalistas e normativos ocidentais no Oriente até suas mais diversas formas de filtragem e resistência cultural (SATO, 2006).

Outro pressuposto importante é o de que os modelos ocidentais de pensamento não são tomados na obra como intrinsecamente positivos ou normativos, e sim contextualizados conforme os diversos momentos e cenários. O "Ocidente", entendem os autores, não se refere a uma unidade ôntica, mas a algo muito complexo, heterogêneo, a tal ponto marcado por fissuras políticas e intelectuais que melhor seria falar de "influências" ocidentais (no plural), mas nunca de um único Ocidente se irradiando pelo globo.

Outra marca forte da obra é sua sensibilidade para tratar "historiografia" num sentido mais amplo do que meramente o stock de obras produzidas pelos historiadores, a produção acadêmica, mas percebendo essa tradição acadêmica dentro de processos mais amplos de constituição de culturas históricas. Basta lembrar que toda produção acadêmica desde Ranke, quando a história surgiu como disciplina acadêmica na Alemanha e logo por todo o Ocidente, concebida sobre os ideais da objetividade científica, da neutralidade axiológica, do método crítico, do amparo às fontes - toda essa mesma produção do século XIX foi artilharia letal na guerra de construção dos mitos nacionais. Dentro e fora da Europa. (DOSSE, 2010; HARTOG, 1988; THIESSE, 1999; BONAFOUX; DE COCK; FALAIZE, 2007).

\footnotetext{
${ }^{9}$ Parte da análise a seguir se compõe da resenha que fiz do livro publicado na História da historiografia. Cf. Malerba (2009a).
} 
A consideração do conceito de cultura histórica é um pilar da obra. Evitando se restringirem à análise textual da bibliografia histórica, os autores trabalham com historiadores e seus textos, porém sem descurar que estes permaneçam imersos em climas de opinião maiores, dentro de culturas originárias, o que leva lggers e Wang a examinarem, para além dos textos, os cenários institucionais, políticos e intelectuais em que se inserem as diversas historiografias. Por exemplo, a formação das cátedras universitárias e a respectiva profissionalização dos historiadores, 0 apoio governamental, o peso dos estudos históricos no cenário político mais amplo no momento da construção das nações-estado e seu impacto vertiginoso na opinião pública da classe média, bem como os efeitos da difusão das discussões científicas como o darwinismo social - no século XIX e no início do XX, foram cuidadosamente levados em conta na análise da escrita histórica do mesmo período.

Para tratar da história da escrita e do pensamento históricos em momento mais recente da era moderna, quando se incrementam os intercâmbios culturais em escala global, o livro se ampara em outro conceito básico, além do de globalização: o de modernização. ${ }^{10}$ Globalização e modernização não se confundem, embora sejam conceitos indissociáveis. A globalização, como demonstrou Felipe Fernández-Armesto em obra fascinante, é tão velha quanto a humanidade (FERNÁNDEZ-ARMESTO, 2009). ${ }^{11}$ Mas a modernização a que se referem nossos autores remete à época mais recente, tendo uma primeira fase entre os séculos XVI e XVIII, uma segunda coincidente com a fase dourada do imperialismo europeu no globo e uma terceira posterior à segunda guerra mundial. Cada um desses momentos, de acordo com os autores, impactou de forma decisiva a consciência histórica e o pensamento e a escrita da história.

O corpo da obra foi desenhado para demonstrar como esses processos da história do pensamento histórico e as diversas fases da globalização moderna se entrelaçam, de modo que a meta dos autores é demonstrar os desdobramentos no pensamento e na escrita histórica em seus contextos intelectuais, sociais e econômicos mais amplos, desde o século XVIII até o início do XXI, abordando as interações entre culturas históricas ocidentais e não ocidentais, numa exposição estrategicamente narrativa.

Por limitação de espaço, não tenho como descer a detalhes do livro, capítulo a capítulo. Mas eu diria que, como todo bom estudo historiográfico, análises e conjeturas dos autores dessa A Global History of Modern Historiography têm caráter heurístico, apontam para tendências e reclamam novos estudos. Seus grandes diferenciais são, por um lado, a aberta rejeição do eurocentrismo e, por outro, a defesa veemente da investigação racional.

Claro que críticas são possíveis. Numa obra com a envergadura dessa, que busca analisar em chave comparativa a história do pensamento histórico em perspectiva global na época moderna, seriam inevitáveis diferenças de ênfase e profundidade na análise, de modo que lacunas e nuances de abordagem são inevitáveis. Elas ficam evidentes, por exemplo, no tratamento dado à análise da historiografia latino-americana ("Da teoria da dependência aos estudos subalternos"), circunscrita em

\footnotetext{
${ }^{10}$ Igualmente por outras vertentes de pensamento, entre as quais se destaca a obra de Weber (1977).

${ }^{11}$ Para uma abordagem que enfatiza o caráter recente do fenômeno, ver Hobsbawn (2005).
} 
cinco páginas e amparada em oito referências bibliográficas, todas em inglês. ${ }^{12}$ Não causará surpresa que especialistas acusem a mesma generalidade no que tange às análises do livro voltadas às tradições historiográficas de outras partes do globo.

O outro livro de história da historiografia com uma perspectiva global que analiso agora, de Daniel Woolf, começa com uma discussão de termos-chave como "história" e "historiografia". Logo no início, percebe-se que, diferentemente de lggers e Wang, o negócio de Woolf não é articular escrita da história com contextos mais abrangentes, sejam econômicos, políticos ou culturais. Em vez disso, ele opta por focar estritamente nas representações escritas do passado em forma historiográfica. Sua opção por privilegiar a escrita da história e os autores é, naturalmente, uma decisão legítima. De outra parte, porém, a produção historiográfica não tem um desenvolvimento autônomo, como um espírito absoluto hegeliano, mas se insere em contextos econômicos, políticos e culturais mais amplos.

Ademais, se Woolf privilegia um formato sem dúvida muito importante da relação entre as sociedades e seu passado (a obra historiográfica), acaba negligenciando outros. O problema que vejo nisso é a ênfase demasiada naquelas representações do passado que foram e ainda são centrais aos países ocidentais, diga-se europeus, mas não no mesmo grau de outras sociedades, nas quais a relação com o passado e suas manifestações são não escritas. Woolf, que se especializou no início da historiografia inglesa moderna, é obstinado em se livrar de qualquer sinal de eurocentrismo. Logo na Introdução, seguindo os passos de Dipesh Chakrabarty, ele afirma que seu livro se alinha ao projeto pós-colonial de "provincializar a Europa" (CHAKRABARTY, 2000). ${ }^{13}$ Mas podemos dizer que sua opção metodológica o conduziu-o a uma ratoeira. Embora seja esse viés que ele deseja superar, em relação aos autores que o precederam, seu livro tem uma embocadura essencialmente eurocêntrica.

Woolf organiza o livro em nove capítulos e um breve Epílogo, usando-se de recursos interessantes como linhas do tempo dos trabalhos mais importantes publicados em cada época, pequenos boxes sobre autores e paradigmas. Também não vou me deter nesses capítulos, que abrangem desde a Mesopotâmia, o Egito e a Antiguidade clássica até os dias de hoje. Mas ele inclui interessantes capítulos sobre China, África e Américas (desde o pré-contato), passando pela cristandade ocidental - com paralelos sobre concepções islâmicas de história ou burocratização da história na China, império bizantino, mongol, cruzadas, reconquista ibérica, contexto atlântico moderno, nacionalismo e profissionalização. Em muitos momentos, o autor consegue pintar quadros que transcendem o eurocentrismo e ajudam a compreender como o conhecimento histórico apareceu em diferentes épocas e partes do planeta. Por outro lado, contudo, pode-se dizer que, embora tenham o mérito de convidar a futuras comparações, muitas vezes se tem a impressão de estar diante de histórias paralelas, que não se conectam.

Woolf segue um modelo difusionista para a história moderna e um comparativo para todos os períodos anteriores. Não deixa de ser irônico o fato de ele tentar superar o mito da "singularidade europeia" e, ao mesmo tempo, reconhecer a existência de um período de "Iluminismo eurasiano" (um iluminismo no Oriente). Ou seja, os grandes

\footnotetext{
12 Para uma análise recente das tendências majoritárias na historiografia da América Latina desde a década de 1960, cf. Malerba (2009b).

${ }^{13} \mathrm{Na}$ mesma linha de Subrahmanyam (1997), ver Hirschi (2012, p. 867).
} 
movimentos culturais ocidentais são usados como parâmetros para análise de outros processos autônomos, não ocidentais. Ao proceder assim, querendo ou não, Woolf age como um colonizador europeu.

Depois de tratar de Ranke no capítulo VII, parece que a narrativa tem nova recaída eurocêntrica. No capítulo VIII, "Clio's Empire" ("O Império de Clio"), Woolf argumenta a favor de tal reorientação porque "a cultura histórica europeia [...] atingiu o zênite de sua influência sobre o resto do mundo nos anos entre 1800 e 1945, precisamente na época em que os países que haviam desenvolvido instituições e códigos disciplinares estavam também exercendo influência política e intelectual sobre o resto do globo" (2014, p. 423). ${ }^{14}$

Conquanto os colonizadores impusessem o próprio "regime de historicidade" não só nas colônias, mas também em outras áreas do mundo, isso poderia ser entendido, nas palavras de Woolf, como uma "conquista por convite" (conquest by invitation), quase como uma anuência, um chamamento dos colonizados para que os realizadores cumprissem sua "missão civilizadora", sem o qual não seria possível entender por que as historiografias com raízes indígenas aceitavam a mudança para métodos e conceitos "modernos" (ocidentais). Aqui estamos, é claro, num ponto crítico para qualquer história global da historiografia. Várias questões podem ser levantadas.

Assim, pode-se perguntar sobre a relação entre superioridade política, econômica, científica e intelectual. Estamos falando de imperialismo. Além disso, ao comparar historiadores asiáticos ou africanos com acadêmicos europeus e norte-americanos, pode-se também questionar até que ponto as semelhanças nos contextos institucionais e nas línguas implicam práticas e funções sociais idênticas ou mesmo comparáveis, cá e acolá.

O longo século XIX seria o período de uma grande homogeneização na escrita da história ou o momento em que pessoas em lugares muito diferentes descobriram ferramentas aparentemente semelhantes e as usaram para determinados fins, condicionados por sua diferente "posição global"? Uma coisa era escrever a história da nação na França; outra era escrevê-la no Brasil, na Índia, na China ou no Senegal. Claro que esses registros podem ser comparados, entretanto também há que se considerar que cumprem funções diferentes e tratam de e com realidades diferentes. Não se trata só da difusão de um método.

Interessa-me em particular o último capítulo, em que Woolf tenta lidar com a "massificação" da escrita histórica no século XX. Divide-se em pequenas seções que tratam de alguns movimentos mais proeminentes, começando com a crise do historicismo e novas tendências na filosofia da história no período entre guerras, discutindo o movimento dos Annales e sua proximidade com a geografia, seguida de uma análise da relação entre a história e as ciências sociais. Em seguida, apresenta nuances da historiografia marxista, questões de gênero, a relação dos povos indígenas com a escrita da história e o papel das abordagens pós-modernas, da história intelectual e da virada linguística. Termina com uma "nova história oral". Não por acaso Woolf usa

\footnotetext{
${ }^{14}$ No original: "European historical culture [...] reached the zenith of its influence over the rest of the world in the years between 1800 and 1945, at precisely the time that the countries which had developed disciplinary codes and institutions were also exercising political and intellectual sway over the rest of the globe" (WOOLF, 2011, p. 399).
} 
a metáfora da "Torre de Babel" no título do capítulo, destacando a especialização em curso e até a fragmentação. ${ }^{15}$

Olhando para trás, sobretudo nesse capítulo, só podemos concordar com o autor quanto à impressão de uma esmagadora explosão da disciplina em milhares de subdisciplinas. No entanto, o que impressiona aqui é que a história global da história proposta por Woolf gasta apenas algumas palavras sobre a tendência mais recente da escrita da história global, que é a linha teórica mestra de sua própria obra.

Seu livro se baseia em extensas pesquisas a respeito de historiadores e escolas de pensamento historiográfico, enquanto sua composição demonstra a intenção do autor de organizar todo o fractal de informação numa narrativa consistente. Como no caso do livro de lggers, podem-se levantar questões sobre detalhes. Sem dúvida, trata-se de uma abordagem inteligente e abrangente, que procura mapear o estado da arte acerca da escrita da história em longa duração e em perspectiva global. Como tal, pode ser percebido como parte de uma sensibilidade nova em nossa cultura histórica que poderíamos chamar de "consciência global". Ao mesmo tempo, o livro traz paradoxos incontornáveis a uma obra que se pretende uma escrita global da história. Além de ser redigida em inglês, as bibliografias que lhe dão suporte também são, em sua maioria, nesse idioma.

\section{CONSIDERAÇÕES FINAIS}

A análise das duas obras, de Iggers e Wang e Woolf, abriria para incontáveis problematizações técnicas aos especialistas do campo da história da historiografia, mas não é isso que me interessa aqui. Concluo passando por algumas questões de fundo, que podem também interessar aos "historiadores globais".

Primeiro, cabe a indagação: que objetos, tempos e espaços podem se beneficiar de uma abordagem global? Ou, antes, que objetos, tempos e espaços podem ser abordados em perspectiva global? De outro modo: podemos estudar globalmente um objeto anterior ao advento da globalização? No caso dos livros mencionados, não me parece que lggers e Wang optaram por escrever uma história global da historiografia moderna por mera comodidade. Antes disso, se não há dúvida de que existia "historiografia", já não é tão seguro sustentar que o mundo fosse uma aldeia global.

Não será fortuito, no mesmo sentido, que o livro de Woolf, o qual pretende abranger todo o globo em todas as épocas, use uma abordagem diferenciada, valendo-se da comparação para o período anterior à modernidade, e um "método difusionista", que acompanha a difusão da racionalidade científica do método crítico a partir da Europa para todo o mundo nos dois últimos séculos.

Outras questões que poderíamos levantar têm menos a ver com a composição e o conteúdo desses livros em particular do que com as histórias globais em geral. Um problema é a narrativa, ou a falta dela. As histórias globais pós-hegelianas, mesmo que bem-estruturadas, como as de Woolf, inevitavelmente lidam com material muito abundante, díspar e complexo demais para suportar um argumento coerente, que não dão conta de narrar e expor uma história compreensível com começo meio e fim.

\footnotetext{
${ }^{15}$ A precisa análise contida na resenha à obra de Woolf feita por Middell (2013).
} 
Escrever um livro que é mais do que a soma de suas partes não é uma tarefa fácil, e a história global de qualquer tema/objeto terá de enfrentar essa dificuldade.

Outro problema específico de histórias globais escritas por um único autor, por mais brilhante que seja, diz respeito à expertise acadêmica e, portanto, à credibilidade autoral. Todos os autores de histórias globais entram no campo como especialistas de uma pequena parte desse vasto campo e não poderão jamais ter a ambição de ser entendedores de tudo o que estão escrevendo. Iggers era um experto em historiografia alemã e contemporânea; Wang, em historiografia chinesa do século XIX; Woolf, em história intelectual francesa moderna.

Fora de seus campos, é inevitável terem de se fiar a uma literatura de segunda mão. Não existe algo como "fonte primária" de história global. "Especialista em história global" é, nesse sentido, uma contradição em termos. Isso ficou claro na história de Iggers, que recorreu a Juan Maiguashca e a mim para revisarmos seu capítulo sobre América Latina na segunda edição do seu livro.

Por fim, pego carona num texto provocativo de Jeremy Adelman (2017), a fim de levantar o problema de que todas as narrativas são seletivas, moldadas tanto pelo que excluem quanto pelo que incluem. Apesar dos mantras da integração e da inclusão em escala planetária, a história global não conseguiu evitar sua própria segregação - começando pela linguagem, questão sublinhada no caso do livro de Woolf. Adelman argumenta, com ironia, como os historiadores que trabalham com temas além-fronteiras nacionais acabaram criando novos muros. Na busca pela coesão acadêmica, o inglês se tornou "globalês" (Globish).

A história global não seria possível sem a globalização da língua inglesa. Este é um dos paradoxos da história global: o fato de o impulso para superar o eurocentrismo contribuir para o anglicismo das vidas intelectuais ao redor do mundo. Como o inglês virou o globalês, tornou-se menos urgente aprender línguas estrangeiras - chave indispensável para nos conectarmos com outras pessoas. No caso de alguém que se proponha a fazer uma história global da historiografia, conhecer as línguas seria um pressuposto básico para trabalhar não só os autores analisados, mas também para ir além da bibliografia de língua nacional desses mesmos autores.

Por outro lado, apesar do advento da história global, a história acadêmica, em qualquer país, tem uma orientação eminentemente nacional. Adelman apresenta números que seriam facilmente replicáveis para o caso brasileiro - nós, que temos uma historiografia ainda majoritariamente nacionalista, no que respeita à abordagem e a campos de investigação.

O que devemos fazer em relação a tudo isso? Em primeiro lugar, como provoca Adelman, as grandes esperanças por narrativas cosmopolitas sobre "encontros" entre Westners e Restners levaram a algumas trocas de sentido único sobre a forma do global. Não é difícil argumentar que a história global é mais uma invenção eurocêntrica para integrar o "outro" numa narrativa cosmopolita em nossos próprios termos. Estamos aqui, mais uma vez, discutindo a pauta ditada em Nova York, Londres ou Paris. No mesmo sentido, até certo ponto, a história global soa como a oficial do mundo de mercado globalizado, que enfatiza a narração de histórias sem fronteiras sobre a de uma suposta "aldeia global", de modo a dar à globalização uma face mais humanizada. ${ }^{16}$

\footnotetext{
${ }^{16}$ Esse argumento é todo de Adelman (2017).
} 
A história global apresenta grandes desafios. Mais que método, exige uma atitude mais cosmopolita, global, ${ }^{17}$ em que se considere, por exemplo, a necessidade de aprender outros idiomas e formas de contar a história. Como podemos aspirar a isso quando lembramos que, num país de dimensões continentais como o Brasil, nem as variações regionais da língua portuguesa é bem aceita?

Por fim, a história global surgiu como um sustentáculo intelectual de uma visão de mundo ocidental pós-muro de Berlim confiante na integração, na conexão, na mobilidade e na união. Mas hoje, numa era de ascensão de discursos hipernacionalistas à la Trump/Bolsonaro/Erdogan/Salvini/Marine Le Pen/Geer Wilders, de crescimento da xenofobia, do ódio, do retorno dos nacionalismos, do conservadorismo, do protecionismo e de aquecimento planetário, parece que o idílio de uma cidadania global foi por água abaixo. As histórias que pretendam esse alcance global não podem prescindir de abordar o lado negro da força, a desintegração, a opressão, a exploração e a resistência em escala global.

\section{REFERÊNCIAS}

ADELMAN, Jeremy. What is global history now? Aeon, 2 March, 2017. Disponível em: https://aeon.co/essays/is-global-history-still-possible-or-has-it-had-its-moment. Acesso em: 10 maio 2018.

ARMITAGE, David; JACOBS, Jaap; VAN ITTERSUM, Martine. Are We All Global Historians Now? An Interview with David Armitage. Itinerario, Cambridge, v. 36, n. 2, p. 7-28, 2012.

BARNES, Harry Elmer. History: Its rise and development. A survey of the progress of historical writing from its origins to the present day. New York: Encyclopedia Americana, 1922.

BERG, Maxine. Writing the History of the Global: Challenges for the $21^{\text {st }}$ Century. Oxford: Oxford University Press, 2013.

BONAFOUX, Corinne; DE COCK, Laurence; FALAIZE, Benoît. Mémoires et histoire à l'Ecole de la République. Paris: Armand Colin, 2007.

CHAKRABARTY, Dipesh. Provincializing Europe: Postcolonial Thought and Historical Difference. Princeton: Princeton University Press, 2000.

COLLINGWOOD, Robin George. A ideia de história. Trad. Alberto Freire. Lisboa: Presença, s/d.

\footnotetext{
${ }_{17}$ Me aproprio aqui da proposta apresentada por Glen Goodman em sua fala no II Encontro Internacional de práticas urbanas: História Urbana e global: novas tendências e abordagens, ocorrido na UECE, em Fortaleza no dia 15 de maio de 2018.
} 
DOSSE, François. História e historiadores no século XIX. In: MALERBA, Jurandir (org.) Lições de história: o caminho da ciência no longo século XIX. Rio de Janeiro: FGV, 2010. p. 15-31.

FERNÁNDEZ-ARMESTO, Felipe. Os desbravadores: uma história mundial da exploração da Terra. Trad. Donaldson M. Garschagen. São Paulo: Companhia das Letras, 2009.

FEUTER, Edward. Histoire de L'Historiographie Moderne. Paris: Félix Alcan, 1915.

FLINT, Robert. History of the Philosophy of History. Edinburgh: William Blackwood \& Sons, 1893.

GEYER, Michel; BRIGHT, Charles. World History in a Global Age. The American Historical Review, Washington, v. 100, n. 4, p. 1034-1060, Oct. 1995.

GOOCH, G. P. History and Historians in the Nineteenth Century. 2 ed. New York: Longmans, Green and Co., 1913.

HARTOG, François. Le XIX siècle et l'histoire: le cas Fustel de Coulanges. Paris: PUF, 1988

HIRSCHI, Caspar. Republicans of Letters, Memory Politicians, Global Colonialists: Historians in Recent Histories of Historiographies. The Historical Journal, Cambridge, v. 55, n. 3, p. 857-881, 2012.

HOBSBAWN, Eric. A era dos extremos. São Paulo: Companhia das Letras, 2005.

IGGERS, Georg G.; WANG, Q. Edward; MUKHERJEE, Supriya. A Global History of Modern Historiography. London: Pearson-Longman, 2008.

LADURIE, Emmanuel Le Roy. L'histoire immobile. Annales: économies, sociétés, civilisations, Paris, p. 673-692, 1974.

MALERBA, Jurandir. Historiografia moderna em perspectiva global. História da historiografia, Ouro Preto, n. 3, p. 167-173, 2009a.

MALERBA, Jurandir. A história na América Latina: ensaio de crítica historiográfica. Rio de Janeiro: Editora FGV, 2009b.

MARQUESE, Rafael; PIMENTA, João Paulo. Tradições de história global na América Latina e no Caribe. História da historiografia, Ouro Preto, n. 17, p. 30-49, abr. 2015.

MIDDELL, Matthias. From Professionalisation to Global Ambitions: the History of History Writing at the Beginning of the Twenty-First Century. International Journal for History, Culture and Modernity, Amsterdam, v. 1, n. 1, p. 87-99, 2013. 
O'BRIEN, Patrick. Historical traditions and modern imperatives for the restoration of global history, Journal of global history, Cambridge, v. 1, p. 3-39, 2006.

RÜSEN, Jörn. História comparativa intercultural. In: MALERBA, Jurandir. A história escrita. São Paulo: Contexto, 2006. p. 115-138.

RÜSEN, Jörn. Western Historical Thinking: An Intercultural Debate. New York: Berghahn Books, 2002.

SANTOS, João Júlio Gomes dos; SOCHACZEWSKI, Monique. História global: um empreendimento intelectual em curso, Tempo, Niterói, v. 23, n. 3, 2017.

SATO, Masayuki. História normativa e história cognitiva. In: MALERBA, Jurandir (org.). A história escrita: teoria e história da historiografia. São Paulo: Contexto, 2006. p. 157-174.

SCHNEIDER, Axel; WOOLF, Daniel (ed.). The Oxford Dictionary of Historical Writing. Vol. V: Historical writing since 1945. Oxford: Oxford University Press, 2011.

SCHULZE, Frederil; FISCHER, Georg. Brazilian History as Global History. Bulletin of Latin American Research, Oxford, p. 1-15, 2018.

SHOTWELL, James T. An Introduction to the History of History. New York: Columbia University Press, 1936.

SUBRAHMANYAM, Sanjay. Connected Histories: Notes Towards a Reconfiguration of Early Modern Eurasia. Modern Asian Studies, Cambridge, v. 31, n. 3, p. 735776, Jul. 1997. Special Issue: The Eurasian Context of the Early Modern History of Mainland South East Asia, 1400-1800.

THIESSE, Anne-Marie. La Création des identités nationales. Paris: Seuil, 1999.

TUCKER, Aviezer (ed.). A Companion to the Philosophy of History and Historiography. Oxford: Blackwell, 2009.

VÖLKEL, Markus. Geschichtsschreibung: Eine Einführung in globaler Perspektive. Köln: Böhlau, 2006.

WEBER, Max. Economía y sociedad: teoria de la organizacion social. México D.F.: Fondo de Cultura Económica, 1977. (3ª reimpressão).

WOOLF, Daniel. A Global History of History. Cambridge: Cambridge University Press, 2011.

WOOLF, Daniel. Uma história global da história. Petrópolis: Vozes, 2014. 


\title{
NOTAS
}

\section{AUTORIA}

Jurandir Malerba: Doutor. Professor titular, Universidade Federal do Rio Grande do Sul, Instituto de Filosofia e Ciências Humanas, Departamento de História, Porto Alegre, RS, Brasil.

\section{ENDEREÇO PARA CORRESPONDÊNCIA}

UFRGS/IFCH, Departamento de História, Av. Bento Gonçalves, 9500, Agronomia, 91509-900, Porto Alegre, RS, Brasil.

\section{ORIGEM DO ARTIGO}

Trata-se do substrato da conferência proferida no II Encontro Internacional de Práticas Urbanas: história urbana e global - novas tendências e abordagens, ocorrido na Universidade Estadual do Ceará (Uece), Fortaleza, em 15 de maio de 2018. Uma versão prévia desse texto foi publicada como capítulo do livro História urbana e global, organizado por Erick Assis de Araújo e João Júlio Gomes dos Santos Júnior e lançado pela editora da Universidade Estadual do Ceará, em 2018.

\section{AGRADECIMENTOS}

$\mathrm{Na}$ pessoa dos organizadores João Júlio Gomes dos Santos e Éric Araújo, agradeço a todos os participantes do II Encontro Internacional de Práticas Urbanas: história urbana e global - novas tendências e abordagens (Uece, Fortaleza, 2018), pelas ricas discussões.

\section{FINANCIAMENTO}

Este artigo foi financiado com bolsa de Produtividade em Pesquisa do Conselho Nacional de Desenvolvimento Científico e Tecnológico (CNPq).

\section{APROVAÇÃO DE COMITÊ DE ÉTICA EM PESQUISA}

Não se aplica.

\section{CONFLITO DE INTERESSES}

Não houve conflito de interesses.

\section{LICENÇA DE USO}

Este artigo está licenciado sob a Licença Creative Commons CC-BY. Com essa licença você pode compartilhar, adaptar, criar para qualquer fim, desde que atribua a autoria da obra.

\section{PUBLISHER}

Universidade Federal de Santa Catarina. Programa de Pós-Graduação em História. Portal de Periódicos UFSC. As ideias expressadas neste artigo são de responsabilidade de seus autores, não representando, necessariamente, a opinião dos editores ou da universidade.

\author{
EDITORES \\ Alex Degan \\ Beatriz Mamigonian \\ Fábio Augusto Morales \\ Flávia Florentino Varella (Editora-chefe) \\ Tiago Kramer de Oliveira \\ Waldomiro Lourenço da Silva Júnior
}

\section{HISTÓRICO}

Recebido em: 28 de maio de 2019

Aprovado em: 23 de julho de 2019 